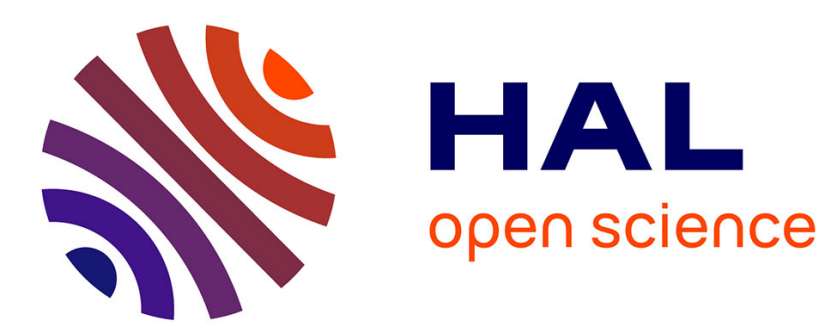

\title{
Radiation-Induced $\alpha$ ' Phase Formation on Dislocation Loops in Fe-Cr Alloys During Electron Irradiation
}

\author{
E. Wakai, A. Hishinuma, Y. Kato, H. Yano, S. Takaki, K. Abiko
}

\section{To cite this version:}

E. Wakai, A. Hishinuma, Y. Kato, H. Yano, S. Takaki, et al.. Radiation-Induced $\alpha^{\prime}$ Phase Formation on Dislocation Loops in Fe-Cr Alloys During Electron Irradiation. Journal de Physique IV Proceedings, 1995, 05 (C7), pp.C7-277-C7-286. 10.1051/jp4:1995733 . jpa-00254027

\section{HAL Id: jpa-00254027 https://hal.science/jpa-00254027}

Submitted on 1 Jan 1995

HAL is a multi-disciplinary open access archive for the deposit and dissemination of scientific research documents, whether they are published or not. The documents may come from teaching and research institutions in France or abroad, or from public or private research centers.
L'archive ouverte pluridisciplinaire HAL, est destinée au dépôt et à la diffusion de documents scientifiques de niveau recherche, publiés ou non, émanant des établissements d'enseignement et de recherche français ou étrangers, des laboratoires publics ou privés. 


\title{
Radiation-Induced $\alpha^{\prime}$ Phase Formation on Dislocation Loops in Fe-Cr Alloys During Electron Irradiation
}

\author{
E. Wakai, A. Hishinuma, Y. Kato*,(1), H. Yano*, S. Takaki* and K. Abiko* \\ Department of Materials Science and Engineering, JAERI, Tokai, Ibaragi 319-11, Japan \\ * Institute for Materials Research, Tohoku University, Sendai, Miyagi 980, Japan
}

\begin{abstract}
Radiation-induced precipitates on dislocation loops in low and high purity Fe-9, -18 and $-50 \% \mathrm{Cr}$ alloys were examined under electron irradiation in a high voltage electron microscope operated at $1 \mathrm{MV}$. Two types of dislocation loops on $\{100\}$ planes with $a<100>$ Burgers vectors and on $\{111\}$ planes with $a / 2<111>$ are formed in high purity $\mathrm{Fe}-\mathrm{Cr}$ alloys. However, only $a<100>$ type loops are formed in low purity alloys, i.e. where carbon concentration is greater than about $60 \mathrm{wt} . \mathrm{ppm}$. The growth rate of the loops formed in $\mathrm{Fe}-9$ and $-18 \mathrm{Cr}$ alloys is faster than that of $\mathrm{Fe}-50 \mathrm{Cr}$ alloy. All of the loops formed at temperatures ranging from $573 \mathrm{~K} \mathrm{to} 973 \mathrm{~K}$, even in the $\left(\sigma+\alpha+\alpha^{\prime}\right)$ phase regions in thermal equilibrium, have moiré fringe contrast due to precipitates identified as $\alpha^{\prime}$ phase. The contrast is very weak in the $\mathrm{Fe}-50 \mathrm{Cr}$ alloy because of coarse distribution of precipitates, while the $\alpha$ ' phase formed in low purity alloys has somewhat larger interplanar spacings that are modified by interstitial impurities. The $\alpha^{\prime}$ phase formation on the loops can be understood by radiation-induced segregation of chromium and interstitial impurity atoms.
\end{abstract}

Keywords: $\mathrm{Fe}$-Cr binary alloy, electron irradiation, radiation-induced segregation, radiation-induced precipitate, RIS, RIP, dislocation loops, impurity effects, Moiré fringe contrast, $\alpha^{\prime}$ phase

\section{INTRODUCTION}

Ferritic steels based on Fe-Cr alloys, less than about $12 \mathrm{wt} \% \mathrm{Cr}$ concentration, have been widely used for structural components in nuclear reactors and/or considered as one of the candidate materials for advanced fission and fusion reactors. Many problems, however, have arisen as a consequence of the exposure to thermal and fast neutron flux. These include radiation hardening, embrittlement, irradiation assisted stress corrosion cracking and so forth. For fusion reactor application, the most serious problems are the degradation in fracture toughness and the shift of ductile-brittle transition temperature to high temperature above the ambient temperature by neutron irradiation. Others are corrosion resistance, tensile and creep strength at elevated temperatures. The ferromagnetic characteristics of these Fe base alloys is also concerned from the viewpoint of magnetic field disturbance generated by magnetic forces.

These characteristics are expected to be improved by increases in the chromium concentration in $\mathrm{Fe}-\mathrm{Cr}$ alloys. Then, $\mathrm{Fe}-\mathrm{Cr}$ alloys containing high chromium are very attractive for fusion application and for fission reactors as well. However, $\mathrm{Fe}$-high $\mathrm{Cr}$ alloys are generally very poor in ductility and no one has considered them as engineering materials. But recently, it has been demonstrated that $\mathrm{Fe}-50 \mathrm{wt} . \% \mathrm{Cr}$ alloy, purified interstitial impurities less than 100 mass $\mathrm{ppm}$ in total, can be easily cold-worked at room temperature without cracking, that is, these alloys can become remarkably ductile after purification[1]. In order to develop these alloys into engineering materials, fundamental and precise research including material behaviour under irradiation especially for nuclear reactor applications is still required.

In a previous paper, the evolution of dislocation loops under electron-irradiation was investigated; two kinds of dislocation loops which are decorated with some precipitation are formed depending on $\mathrm{Cr}$ concentration and interstitial impurity levels in the alloys[2]. The present study focuses on the behaviour of

\footnotetext{
(1) Present address: Technical Research Division, Kawasaki Steel Corporation, Chuo-ku, Chiba 260, Japan
} 
the precipitation on the loops formed in $\mathrm{Fe}-(9-50) \mathrm{wt} . \% \mathrm{Cr}$ alloys as a function of chromium concentration and impurity level.

\section{Experimental procedure}

The samples used are high and low purity $\mathrm{Fe}-(9,18$ and 50)wt.\% $\mathrm{Cr}$ binary alloys, which are designated $\mathrm{Fe}-9 \mathrm{Cr}, \mathrm{Fe}-18 \mathrm{Cr}$, and $\mathrm{Fe}-50 \mathrm{Cr}$, respectively. The high purity alloys were melted from high purity iron of 99.995 mass \% purity and high purity chromium of 99.98 mass \% in a high vacuum of $10^{-6}$ torr with a high frequency induction furnace. The low purity alloys were made from conventional purity metals of 99.9 mass \% iron and about 99.9 mass \% chromium. The chemical compositions of these alloys are given in table 1 . The total amounts of interstitial impurities in the high purity alloys shown at the bottom of the column are less than 100 mass ppm, while the total impurity concentrations in the low purity alloys are greater than 250 mass ppm. The alloys were rolled down to sheets of $200 \mu \mathrm{m}$ in thickness and then normalized at $1,323 \mathrm{~K}$ for $1.8 \times 10^{3} \mathrm{~s}$ in a vacuum followed by air-cooling to obtain large grain size with a single $\alpha$-ferrite phase. The Fe-9Cr alloys were tempered additionally at $1,123 \mathrm{~K}$ for $3.6 \mathrm{x} 10^{3} \mathrm{~s}$ in a vacuum with furnace cooling after the normalizing heat treatment in order to avoid the appearance of a $\gamma$ phase in the ferritic phase.

Electron irradiations and simultaneous observations were performed at temperatures ranging from 573 to $1,023 \mathrm{~K}$ in a high voltage electron microscope (HVEM) operated at $1 \mathrm{MV}$. The electron flux measured using a Faraday gauge located above the fluorescent screen is $4.5 \times 10^{23} \mathrm{e} / \mathrm{m}^{2} \mathrm{~s}$, which corresponds to $1.75 \times 10^{-3} \mathrm{dpa} / \mathrm{s}$ assuming a threshold displacement energy of $25 \mathrm{eV}$. The irradiation was continued up to about $1 \mathrm{dpa}$. Detailed observations and analyses were carried out using a $200 \mathrm{kV}$ transmission electron microscope with an energy dispersive $\mathrm{X}$-ray spectroscope after the irradiation experiments.

Table 1.

Chemical compositions of low and high purity $\mathrm{Fe}-\mathrm{Cr}$ alloys used.

The symbol - represent the unanalyzed element.

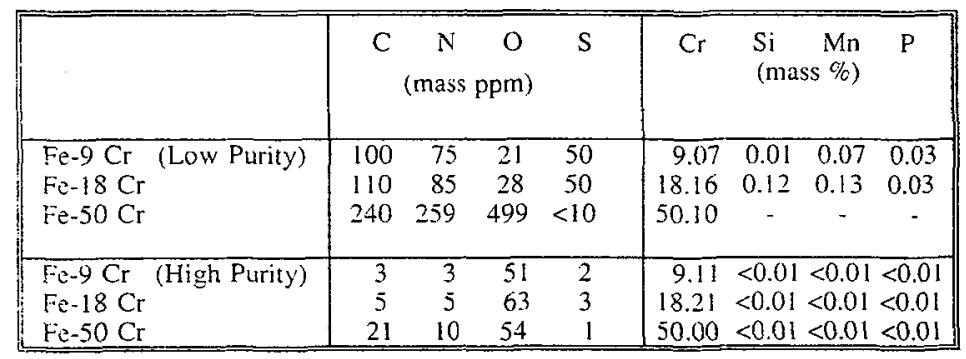

\section{Results}

\subsection{Development of dislocation loops}

Dislocation loops formed in high purity Fe-50Cr irradiated at 673,723 , and $773 \mathrm{~K}$ to 1 dpa are shown in figs. 1(a), 1(b), and 1(c), respectively. The photographs were taken at room temperature from near [001] pole with $g=[110]$ vector under an exact bragg diffraction. Two types of dislocation loops are observed; one is on $\{100\}$ planes with $a<100>$ Burgers vectors and another is on $\{111\}$ planes with $a / 2$ <111. 
These loops, shown in fig. 1 , correspond to rod-like shapes parallel to $<100\rangle$ directions and complicated shapes, respectively. The loops formed at $673 \mathrm{~K}$ are the most complicated in shape because they are decorated with some precipitates. At increasing irradiation temperatures, the shape of the loops becomes a simple ellipse. In low purity $\mathrm{Fe}-50 \mathrm{Cr}$, however, only one of loops on $\{100\}$ planes with $a<100\rangle$ is observed. In either case, very weak moiré fringe contrast is observed on the loops.

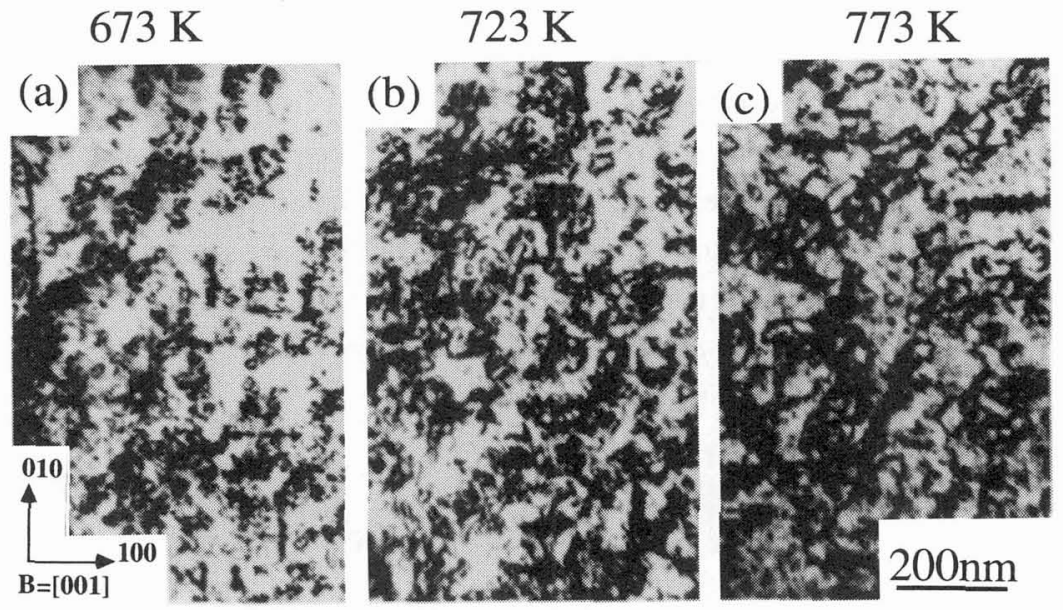

Fig. 1 Dislocation loops observed in high purity $\mathrm{Fe}-50 \mathrm{Cr}$ alloys irradiated at (a) $573 \mathrm{~K}$, (b) $673 \mathrm{~K}$, and (c) $773 \mathrm{~K}$ by $1 \mathrm{MeV}$ electrons with a flux of $4.5 \times 1023 \mathrm{e}$. $/ \mathrm{m}^{2} \mathrm{~s}$ during $600 \mathrm{~s}$ up to $1.05 \mathrm{dpa}$.

In $\mathrm{Fe}-9 \mathrm{Cr}$ and $\mathrm{Fe}-18 \mathrm{Cr}$, on the other hand, two kinds of loops of $a<100>$ and $(a / 2)<111>$ in high purity alloys and only one $a<100>$ type loop in low purity alloys are observed. All of these loops are decorated with some precipitates and have a clear moiré fringe contrast as shown in a previous paper[2].

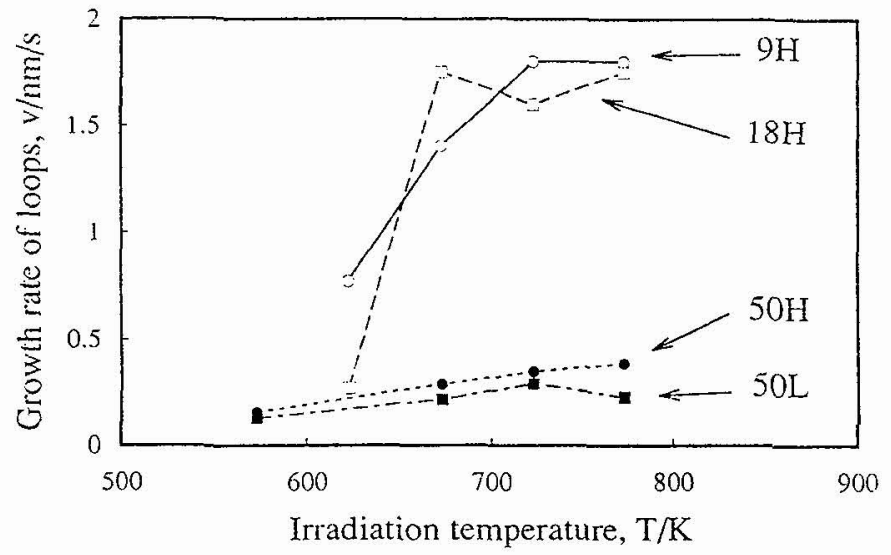

Fig. 2 Growth rates of dislocation loops in high and low purity $\mathrm{Fe}-\mathrm{Cr}$ alloys under $1 \mathrm{MeV}$ electron irradiation at a damage rate of $1.75 \times 10^{-3} \mathrm{dpa} / \mathrm{s}$.

Figure 2 shows the growth rate of $a<100>$ type loops formed in $\mathrm{Fe}-9 \mathrm{Cr},-18 \mathrm{Cr}$, and $-50 \mathrm{Cr}$. The growth rate of the loops formed in $\mathrm{Fe}-50 \mathrm{Cr}$ is clearly slower than that in the alloys with a lower chromium 
content, especially at higher temperatures. The number densities of the loops in these high purity alloys are nearly equal to each other and the value is about $1020 / \mathrm{m}^{3}$ at $723 \mathrm{~K}$. The effect of impurities on the growth and number density of the loops is not so large in $\mathrm{Fe}-50 \mathrm{Cr}$ but in $\mathrm{Fe}-9 \mathrm{Cr}$ and $\mathrm{Fe}-18 \mathrm{Cr}$ is recognized as the slow growth rate and increase of the density of the loops.

\subsection{Identification of precipitates on dislocation loops}

Fig. 3 shows the moiré fringe contrast observed on dislocation loops in high purity $\mathrm{Fe}-9 \mathrm{Cr}$ irradiated at $673 \mathrm{~K}$ to $1 \mathrm{dpa}$. The photographs in figs. 3(a) and 3(b) are taken under bragg diffraction conditions with a slight deviation $(s>0)$ and an exact one $(s=0)$ using $g=[110]$ vector near [111] pole, respectively. The small black dots in fig. 3(a) are thought to be precipitates. On changing the diffraction conditions from $s>$ 0 to $s=0$, as shown in fig. 3(b), the moire fringe contrast becomes visible on the loops. The fringe is formed by the interference effect of the electron beam passing between matrix and precipitate. The fringe distance is measured to be $23 \mathrm{~nm}$ and then, the interplanar spacing of precipitates between $\{110\}$ planes is calculated as $2.034 \times 10^{-1} \mathrm{~nm}$, which corresponds to that of the $\alpha^{\prime}$ phase.

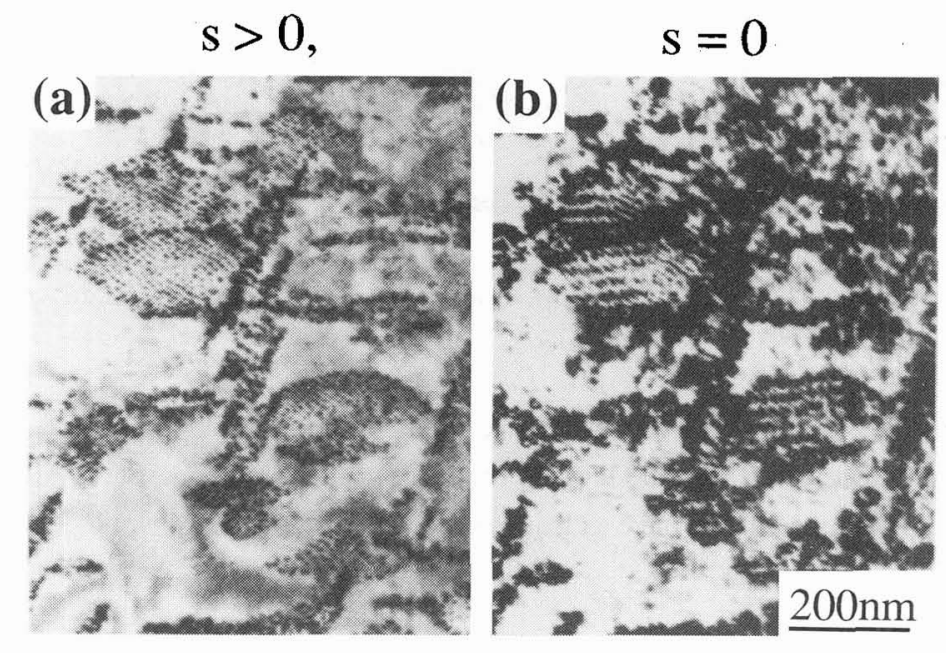

Fig. 3 Microstructures of dislocation loops in high purity $\mathrm{Fe}-9 \mathrm{Cr}$ alloy irradiated at $673 \mathrm{~K}$. The photographs taken under (a) a slightly deviation from bragg diffraction and (b) an exact bragg one.

The loop morphology is shown in fig. 4 as a function of irradiation temperature. The precipitates formed at $573 \mathrm{~K}$ are observed as isolated black dots on the loops, but they become semi-continuous lines accompanied by moiré fringe contrast as irradiation temperatures increase up to $773 \mathrm{~K}$. At a higher temperature of $973 \mathrm{~K}$, some loops with fringe contrast are observed but others with no fringe. Above $1,023 \mathrm{~K}$, no formation of dislocation loops is observed. The interplanar spacings of precipitates formed in high and low purity $\mathrm{Fe}-9 \mathrm{Cr}$, calculated from the moiré fringe contrast, are plotted in fig. 5 as a function of the irradiation temperature. The results show that the spacings about $2.035 \times 10^{-1} \mathrm{~nm}$ corresponding to the $\alpha^{\prime}$ phase do not change with irradiation temperature and no other phase like $\sigma$ phase form, while in low purity $\mathrm{Fe}-9 \mathrm{Cr}$, the slightly larger interplanar spacing of $2.040 \times 10^{-1} \mathrm{~nm}$ is observed. Similar results are also obtained in $\mathrm{Fe}-18 \mathrm{Cr}$. In the case of $\mathrm{Fe}-50 \mathrm{Cr}$ alloys, however, the fringe contrast is very weak, as described above, and cannot be analyzed. 


\section{$573 \mathrm{~K}$}

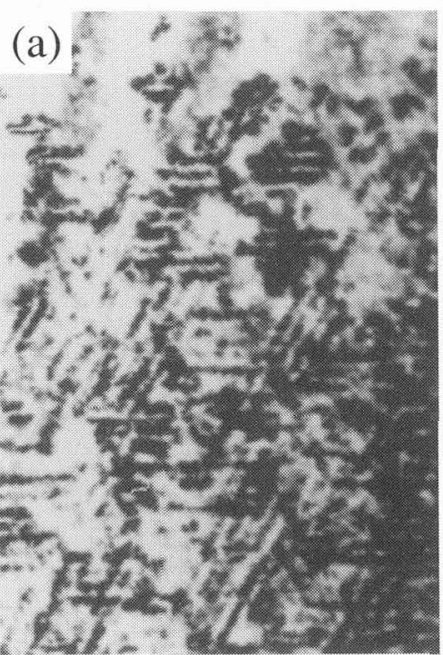

$673 \mathrm{~K}$

(b)

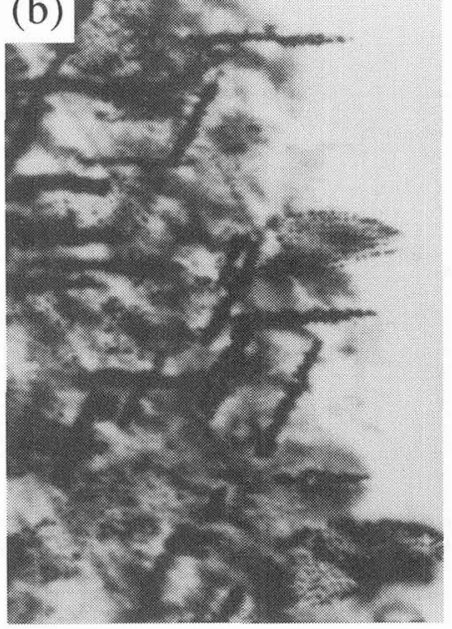

$773 \mathrm{~K}$

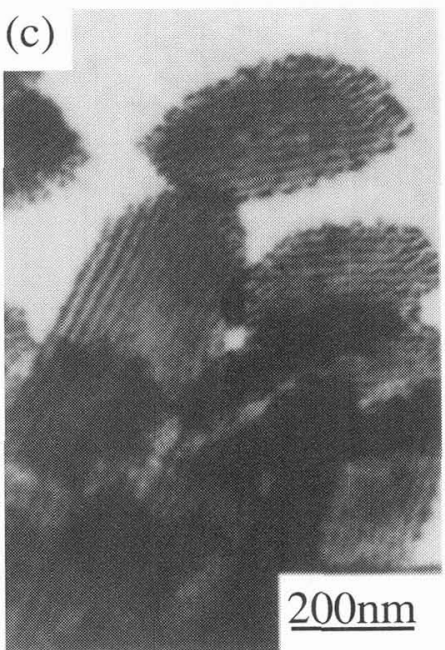

Fig. 4 Dislocation loops observed in high purity Fe-9Cr alloys irradiated at (a) $573 \mathrm{~K}$, (b) $673 \mathrm{~K}$, and (c) $773 \mathrm{~K}$ by $1 \mathrm{MeV}$ electrons with $4.5 \times 1023 \mathrm{e}-/ \mathrm{m}^{2} \mathrm{~s}$ up to $1.05 \mathrm{dpa}$ for $600 \mathrm{~s}$.

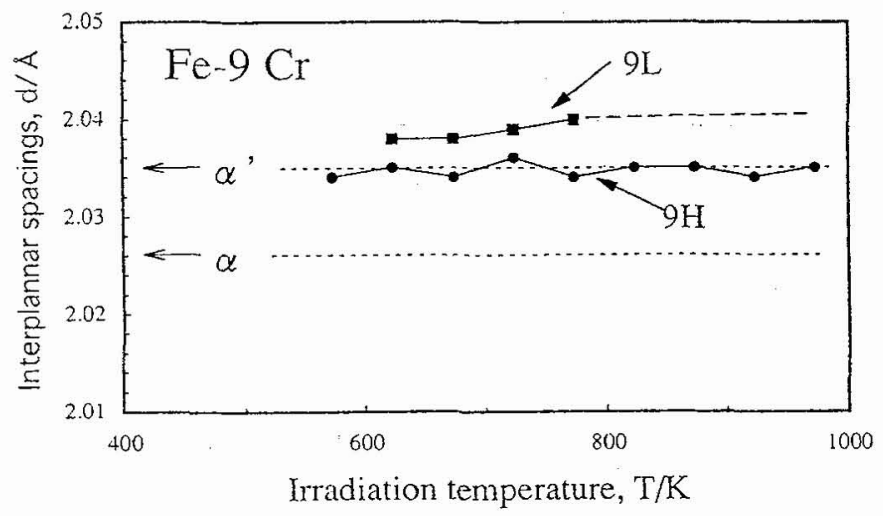

Fig. 5 Interplannar spacing of precipitates is plotted as a function of irradiation temperature in high and low purity $\mathrm{Fe}-9 \mathrm{Cr}$ alloy.

\subsection{Radiation-induced segregation (RIS) to grain boundaries}

Distributions of $\mathrm{Cr}$ concentration across the high-angle grain boundaries in high purity $\mathrm{Fe}-9$ and $-50 \mathrm{Cr}$ irradiated at $773 \mathrm{~K}$ up to $3 \mathrm{dpa}$ are shown in figs. $6(\mathrm{a})$ and $6(\mathrm{~b})$, respectively, as a function of distance from the grain boundaries. The beam diameters used were $2 \mathrm{~nm}$ for $\mathrm{Fe}-50 \mathrm{Cr}$, and $5 \mathrm{~nm}$ for Fe-9Cr because the beam was hardly focused due to the strong ferromagnetic material. In either case, it is shown that 
chromium is depleted from the grain boundaries under irradiation. In $\mathrm{Fe}-9 \mathrm{Cr}$, where the larger beam size is used, the ratio of depletion of chromium concentration at grain boundary to that in the matrix is larger than in $\mathrm{Fe}-50 \mathrm{Cr}$.

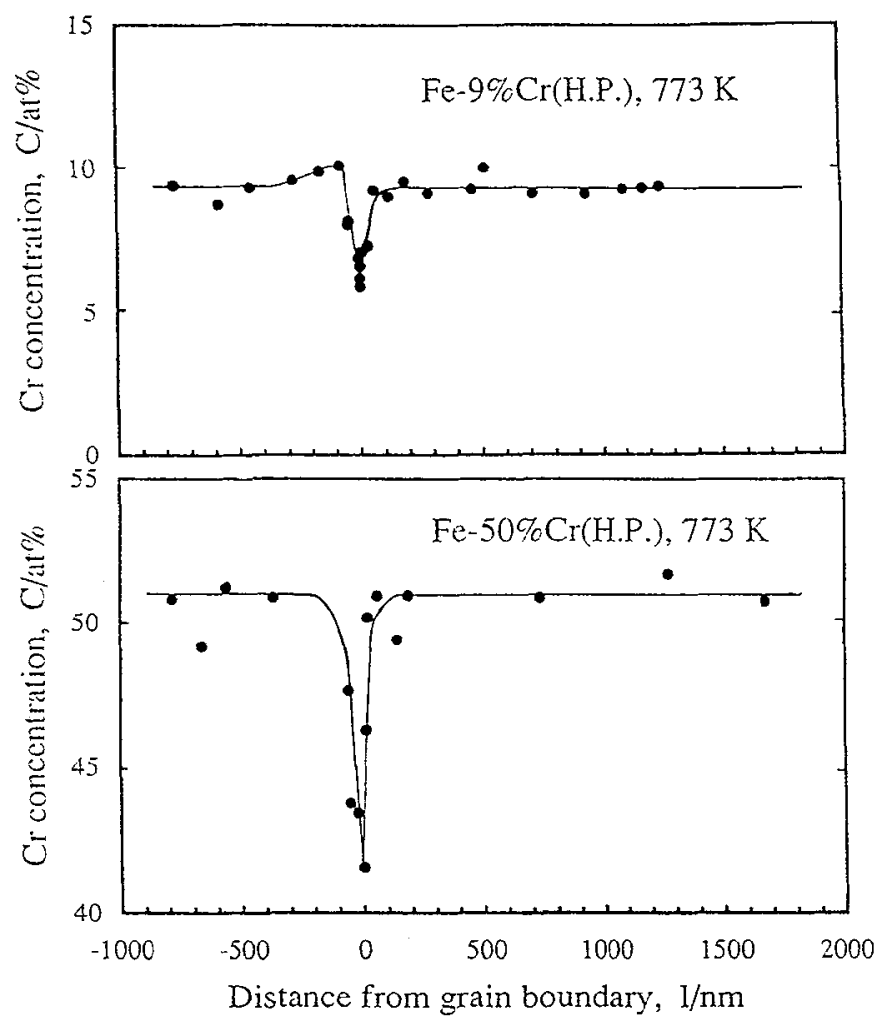

Fig. 6 Cr concentration as a function of the distance from grain boundary in (a) $\mathrm{Fe}-9 \mathrm{Cr}$ and (b) $\mathrm{Fe}-50 \mathrm{Cr}$ alloys irradiated at $773 \mathrm{~K}$ to $3 \mathrm{dpa}$.

\section{Discussion}

\subsection{Effect of $\mathrm{Cr}$ concentration on $\alpha^{\prime}$ precipitate formation on dislocation loops}

The phase decomposition of $\alpha$ phase to $\left(\alpha+\alpha^{\prime}\right)$ in hot conditions is generally easier in Fe-Cr alloys with high chromium concentration. On the other hand, decomposition seems to be difficult in higher chromium alloys under irradiation as described in section 3. Before considering the cause, we shall discuss diffraction conditions to observe the moire fringe contrast on the loops and irradiation temperature effects on precipitate formation behaviour.

A moire fringe is scarcely observed on the $\mathrm{Fe}-50 \mathrm{Cr}$ loops even though the precipitate contrast is observed as shown in fig. 1 . In this case, any extra diffraction spots formed by the $\sigma$ phase and/or carbide precipitates[3] are not observed. If the precipitate is $\alpha^{\prime}$ phase, it is difficult to observe extra spots formed by $\alpha^{\prime}$ phases, because the interplanar spacings of $\{110\}$ planes for $\alpha$ and $\alpha^{\prime}$ phases are very close to each other; $2.026 \times 10^{-1} \mathrm{~nm}$ for $\alpha$ phase and $2.035 \times 10^{-1} \mathrm{~nm}$ for $\alpha^{\prime}$ phase. Using a diffraction condition of $g$ $=[110]$ vector, the width of moiré fringe generated by the interference between two crystals of $\alpha$ and $\alpha^{\prime}$ phases is estimated as $21 \mathrm{~nm}$. On the other hand, the actual interval among precipitates is $27 \mathrm{~nm}$ as 
observed in fig. 1(a). As a result, the clear moire fringe cannot be formed except by the large precipitates. In case of $\mathrm{Fe}-9 \mathrm{Cr}$, however, the moiré fringe can be easily observed because the interval between precipitates is $11.5 \mathrm{~nm}$ and is smaller than the width of the moire fringe between the $\alpha$ and $\alpha^{\prime}$ phases.

In hot environments, the phase transition from $\left(\alpha+\alpha^{\prime}\right)$ phases to $\left(\sigma+\alpha+\alpha^{\prime}\right)$ phases occurs at $720 \mathrm{~K}$. However, the moiré fringe formation on the loops is observed between 573 and $973 \mathrm{~K} \mathrm{in} \mathrm{Fe}-9 \mathrm{Cr}$ as shown in figs. 4 and 5. The interplanar spacings are constant even at temperatures above $720 \mathrm{~K}$ as shown in fig. 5; the precipitates formed on the loops are not $\sigma$ phase but $\alpha^{\prime}$ phase. These facts may indicate that the temperature of the phase transformation in the dislocation loops of the $\mathrm{Fe}-\mathrm{Cr}$ alloy under irradiation exists at higher temperature than $720 \mathrm{~K}$. Indeed, in some studies of the phase transition temperature, shifts in the other alloys were reported[4-12]. In this study, the temperature shift is probably caused by RIS of chromium atoms and chemical disordering by replacement collision sequences. They may influence the chemical ordering, the temperature of phase transition and the formation of the $\sigma$-phase.

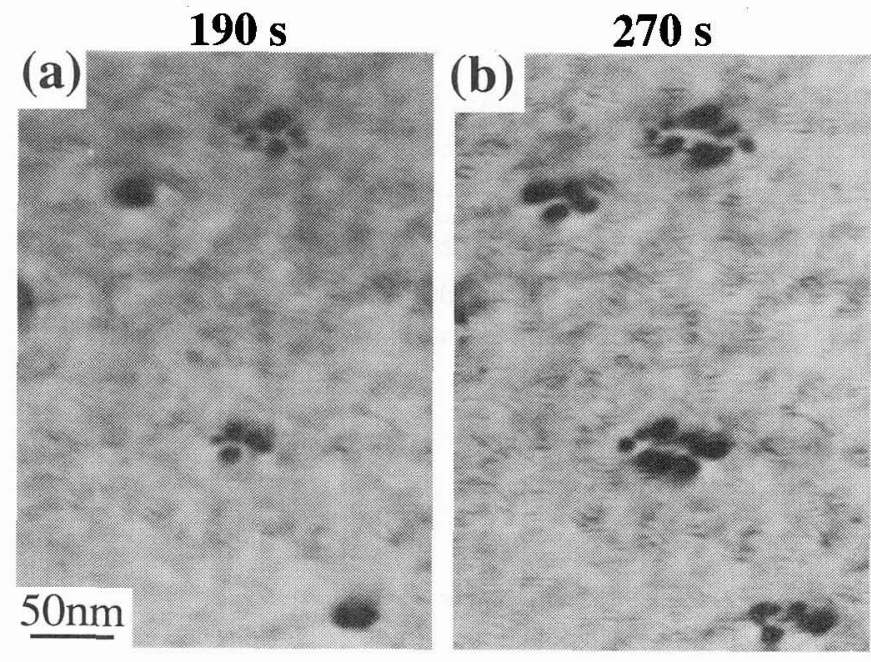

Fig. 7 Precipitates are formed at $673 \mathrm{~K}$ near the edge of small dislocation loops at an early stage in high purity $\mathrm{Fe}-18 \mathrm{Cr}$ alloys. Afterward, they are again formed near the edge of the loops.

Finally, we shall think about the mechanism of $\alpha^{\prime}$ phase formation on the loops during irradiation. Fig. 7 shows the process of formation and growth of the precipitates on the loops in high purity $\mathrm{Fe}-18 \mathrm{Cr}$ irradiated at $673 \mathrm{~K}$. The $\alpha^{\prime}$ precipitates formed are formed at the edge of the loops at an early stage. They then grow and are again formed at the edge of the loops grown. From the result, it is expected that the nucleation and growth of $\alpha^{\prime}$ precipitates may be caused by $\mathrm{Cr}$ segregation to the loops in the opposite direction. We propose a model of the $\alpha^{\prime}$ phase formation mechanism on the loops as described below: $\mathrm{Cr}$ atoms segregate to the loops in the opposite direction; interstitial impurities also segregate to the loops. Thereafter, the complex of $\mathrm{Cr}$ atoms with interstitial impurities may be formed near the edge of the loops, and $\mathrm{Cr}$ atoms become easy to trap at the complex. In this way, the nucleus of an $\alpha^{\prime}$ phase can be formed. Once nuclei of the $\alpha^{\prime}$ phase are formed near the loops, the growth of an $\alpha^{\prime}$ phase is enhanced in comparison with the progress of thermal decomposition of the $\alpha$ phase to $\left(\alpha+\alpha^{\prime}\right)$ phases[13] because $\mathrm{Cr}$ 
atoms are supplied by RIS. Therefore, the loops decorated with $\alpha^{\prime}$ precipitates are formed as shown in fig. 3 , and in low purity alloys the interplanar spacings of the $\alpha^{\prime}$ phase formed are modified by impurity segregation.

\subsection{Effect of $\mathrm{Cr}$ concentration on growth rate of loops and RIS}

The behaviour of $\mathrm{Cr}$ segregation at grain boundaries in $\mathrm{Fe}-50 \mathrm{Cr}$ is very similar to that in $\mathrm{Fe}-9 \mathrm{Cr}$ alloy, as shown in fig. 6. The volume size of $\mathrm{Cr}$ atoms in $\mathrm{Fe}$ is $4.3 \%$ [14], and the depletion of $\mathrm{Cr}$ concentration at grain boundaries is understood by the volume size effect[15-17]. In order to compare the efficiency of amount of $\mathrm{Cr}$ segregation to grain boundary between $\mathrm{Fe}-9$ and $-50 \mathrm{Cr}$, it is assumed to be described as:

$$
\{(\mathrm{Cg}-\mathrm{Cm}) / \mathrm{Cm}\} \times 100(\%)
$$

where $\mathrm{Cg}$ and $\mathrm{Cm}$ are chromium concentration at the grain boundary and in the matrix, respectively. The amounts of segregation estimated by equation of (3-1) in the $\mathrm{Fe}-9$ and $-50 \mathrm{Cr}$ are evaluated to be 30 and 20 $\%$, respectively; the efficiency in $\mathrm{Fe}-9 \mathrm{Cr}$ is higher than that in $\mathrm{Fe}-50 \mathrm{Cr}$. Taking into account the probe size of 5 and $2 \mathrm{~nm}$ in $\mathrm{Cr}$ concentration measurement for $\mathrm{Fe}-9 \mathrm{Cr}$ and $\mathrm{Fe}-50 \mathrm{Cr}$, respectively, the efficiency would be further increased. The cause of RIS degradation in the $\mathrm{Fe}-50 \mathrm{Cr}$ is thought to be that the effective volume of $\mathrm{Cr}$ atoms in diffusion of $\mathrm{Cr}$ atoms through the vacancy mechanism decreases with increasing $\mathrm{Cr}$ concentration more than the solid solution concentration; the preferential flow of $\mathrm{Cr}$ atoms to the grain boundary would be decreased with $\mathrm{Cr}$ concentration. On the other hand, as described in section 3.1, the reason why the growth rate of $\mathrm{Fe}-50 \mathrm{Cr}$ is slow is thought to be the increase in trapping of interstitial atoms at the site of $\mathrm{Cr}$ atoms.

As described in a previous paper[2], $\mathrm{Cr}$ concentration at dislocation loops is enriched in high purity $\mathrm{Fe}-9 \mathrm{Cr}$, but $\mathrm{Cr}$ concentrations at grain boundaries are depleted in both the $\mathrm{Fe}-9$ and $-50 \mathrm{Cr}$ as shown in fig. 6. These results are inconsistent with each other. Since the volume size of $\mathrm{Cr}$ atom in $\mathrm{Fe}$ is oversize, $\mathrm{Cr}$ concentration should be decreased at sinks of point defects, i.e., at grain boundaries and dislocation loops. Thus, the reason for the increase of $\mathrm{Cr}$ concentration at the loops is owing to the result of concentration measurement on the edge of the very small loops with precipitates as seen in fig. 3 .

\subsection{Effects of purity level and $\mathrm{Cr}$ concentration on dislocation loops}

According to a proposed formation model[18-21] of dislocation loops in bec materials, dislocation loops nucleate on $\{110\}$ planes with $<110>$ burgers vectors; the loops formed transfer to $\{100\}$ planes with $<100>$ vectors and $\{111\}$ planes with $(1 / 2)<111>$ vectors soon after loop formation. So far, some researchers have observed the $<100>$ type loops formed in Fe-Cr alloys[22] and in the other $<100>$ and $<111>$ type loops[23-26]. On the other hand, in high purity iron the loops formed were $<111>$ and $<100>$ types[27]. The reason why these factors affect the formation process of the loop was unknown. However, as shown in section 3.2, it is found that in high purity $\mathrm{Fe}-\mathrm{Cr}$ alloys the loops formed by electron irradiation are two kinds of $<100>$ and $<111>$ types, and this depends on the purity level of the materials and has no dependence on $\mathrm{Cr}$ concentration from 0 to $50 \% \mathrm{Cr}$. Thus, it is important to know what impurity affects the formation process of the loops. As reported in a previous paper[2], in a high purity $\mathrm{Fe}-30 \mathrm{Cr}$ alloy containing 57 mass ppm carbon and 10 mass ppm nitrogen atoms, the loops formed are of only one type, while in all low purity $\mathrm{Fe}-\mathrm{Cr}$ alloys which include 300 mass ppm impurity concentration including 100 
mass ppm carbon and 75 mass ppm nitrogen atoms, the loops observed are 100 type. Consequently, it is found that the kinds of loops formed decrease in $\mathrm{Fe}-\mathrm{Cr}$ alloys containing about 60 mass ppm carbon concentration. The increase of total interaction of dislocation with carbon atoms is thought to exert an effect on the transfer process of the loop.

\section{CONCLUSION}

Electron radiation-induced precipitates on dislocation loops formed in $\mathrm{Fe}-9,-18$, and $-50 \mathrm{Cr}$ alloys including impurity effects were examined using a high voltage electron microscope operated at $1 \mathrm{MV}$, and the results obtained are summarized as follows;

(1) Two kinds of dislocation loops are formed in high purity Fe-Cr alloys; one is on $\{100\}$ planes with $a<100>$ Burgers vectors and another is on $\{111\}$ planes with $a / 2<111>$. Only $a<100>$ type loops are formed in low purity alloys containing carbon concentrations greater than about 60 mass ppm.

(2) The loops formed in $\mathrm{Fe}$-Cr alloys irradiated at temperatures of 573 to $973 \mathrm{~K}$ are decorated with $\alpha^{\prime}$ precipitates, formation of which is enhanced by the radiation-induced segregation (RIS) mechanism. The $\alpha^{\prime}$ precipitates results in moiré fringe contrast on the loops by an interference effect between matrix and precipitates.

(3) The moiré fringe contrast is observed very clearly in $\mathrm{Fe}-9$ and $-18 \mathrm{Cr}$ alloys but very weakly in $\mathrm{Fe}-$ $50 \mathrm{Cr}$ alloy due to the low number density of precipitates.

(4) The interplanar spacing of $\alpha$ precipitate observed in low purity alloys, which is modified with impurity segregation is greater than that in high purity alloys.

(5) The growth rate of dislocation loops in $\mathrm{Fe}-50 \mathrm{Cr}$ alloy is slower than that in $\mathrm{Fe}-9$ and $-18 \mathrm{Cr}$ alloys.

(6) Depletion of chromium concentration at grain boundaries through the RIS mechanism is observed in $\mathrm{Fe}-\mathrm{Cr}$ alloys. The ratio of depletion of $\mathrm{Cr}$ concentration at the grain boundary to that in the matrix in $\mathrm{Fe}$ $9 \mathrm{Cr}$ alloy is greater than in $\mathrm{Fe}-50 \mathrm{Cr}$ alloys. The facts can be also explained by the increase in the effective volume of $\mathrm{Cr}$ atoms by the vacancy mechanism.

\section{Acknowledgements}

The authors wish to thank Mr. K. Fukai for technical support with electron microscopes.

\section{REFERENCES}

[1] K. Abiko: Proceedings of UHPM-94, K. Abiko, K. Hirokawa, and S. Takaki, eds., 1 (1994), 522.

[2] E. Wakai, et al.: Proceedings of UHPM-94, K. Abiko, K. Hirokawa, and S. Takaki, eds., 1 (1994), 488.

[3] K. W. Andrews, D. J. Dyson and S. R. Keown: Interpretation of electron diffraction pattern, plenum press, (1967).

[4] R. Cauvin and G. Martin: J. Nucl. Mater., 83 (1979), 67.

[5] R. Cauvin and G. Martin: Phys. Rev., B23 (1981), 3322.

[6] R. Cauvin and G. Martin: Phys. Rev., B23 (1981), 3333.

[7] R. Cauvin and G. Martin: Phys. Rev., B23 (1982), 3385. 
[8] A. Barbu and A. Ardell: Scripta Met., 9 (1975), 1233.

[9] A. Barbu and A. Ardell: Scripta Met., 11 (1977), 771.

[10] K. Janghorban and A. J. Ardell: J. Nucl. Mater., 85\&86 (1979), 719.

[11] L. Weaver and A. Ardell: In effects of radiation on materials, D. Kramer et al, eds., ASTM, STP, 725 (1981), 610.

[12] R. K. Williams, J. O. Stiegler and F. W. Wiffen: In ORNL report TM-4500 (1974), 1514.

[13] P. S. Rundaman, J. Stringer and R. I. Jaffee eds.: Phase stability in metals and alloys, Mcgraw-Hill, (1967), 63.

[14] H. K. King: J. Nucl. Sci., 1 (1966), 79.

[15] P. R. Okamoto and H. Wiedersich: J. Nucl. Mater., 53 (1974), 336.

[16] T. Ezawa, E. Wakai, and R. Oshima: Defect and diffusion forum, $95-98$ (1993), 237.

[17] E. Wakai, T. Ezawa, T. Tanabe and R. Oshima: Mater. Trans. JIM, 33 (1992), 884.

[18] E. G. Schilling: J. Nucl. Mater., 69\&70 (1978), 465.

[19] B. L. Eyre and R. Bullough: Phil. Mag., 12 (1965), 31.

[20] R. Bullough and R. C. Perrin: In Proceedings of the Royal Cociety, London, A305 (1968), 541.

[21] R. Bullough, M. H. Wood, and E. A. Little: Effects of Radiation on Materials; 10th. Conference, D. Kramer, H. R. Brager, and J. S. Perrin, Eds., American Society for Testing and Materials, ASTM STP 725 (1981), 593.

[22] S. Ohnuki, H. Takahashi and T. Takeyama: J. Nucl. Mater., $122 \& 123$ (1984), 317.

[23] D. S. Gelles: Annual Progress Report for Fusion Year; A. Koyama and F. A. Garner, Eds., National Institute for Fusion Science, (1991), 348.

[24] L. L. Horton and J. Bentley: 13th International Symposium (part1), F. A. Garner, N. H. Packan, and A. S. Kumar, Eds., American Society for Testing and Materials, Philadelphia, ASTM STP 955 (1987), 466.

[25] R. Bullough, M. H. Wood, and E. A. Little: Effects of Radiation on Materials; 10th. Conference, D. Kramer, H. R. Brager, and J. S. Perrin, Eds., American Society for Testing and Materials, ASTM STP 725 (1981), 593.

[26] T. Muroga, A. Yamaguchi and N. Yoshida: Effects of radiation on materials: 14 th International Symposium, vol.1, ASTM STP 1046 (1989),396.

[27] A. E. Ward and S. B. Fisher: J. Nucl. Mater., 166 (1989), 227. 